\title{
A Valine-to-Cysteine Mutation Further Increases the Oxygen Tolerance of Escherichia coli NiFe Hydrogenase Hyd-1
}

\author{
Melisa del Barrio, Chloé Guendon, Arlette Kpebe, Carole Baffert, Vincent Fourmond, Myriam \\ Brugna, ${ }^{*}$ and Christophe Léger* \\ Aix Marseille Univ., CNRS, Bioénergétique et Ingénierie des Protéines, 13009, Marseille, France \\ E-mail: mbrugna@imm.cnrs.fr; christophe.leger@imm.cnrs.fr
}

\begin{abstract}
Some NiFe hydrogenases are particularly resistant to $\mathrm{O}_{2}$, as a result of either the natural presence of a particular FeS cluster or the artificial replacement of a conserved valine residue near the $\mathrm{Ni}$ site. We show that the two protective effects can be combined in a single enzyme, by constructing and characterizing the $\mathrm{V} 78 \mathrm{C}$ variant of the naturally $\mathrm{O}_{2}$-tolerant E. coli NiFe hydrogenase Hyd-1. We elucidate the effect of the mutation by comparing the kinetics of inhibition by $\mathrm{CO}$ and $\mathrm{O}_{2}$ of a number of wild-type forms and valine-to-cysteine variants of NiFe hydrogenase.

This is the authors' version of doi:10.1021/acscatal.9b00543
\end{abstract}

Hydrogenases are the enzymes that oxidize and produce $\mathrm{H}_{2}$. They are all inhibited by $\mathrm{O}_{2}$, although the extent, kinetics and nature of the inactivation vary greatly. Here we discuss the hydrogenases that bear a NiFe dinuclear active site. The so-called "O $\mathrm{O}_{2}$-tolerant" NiFe hydrogenases embed an unusual [4Fe-3S] cluster near the active site, as part of a redox chain that mediates intramolecular electron-transfer. The general consensus is that this cluster causes resistance to $\mathrm{O}_{2}{ }^{1,2}$ (see, however, ref. 3). On the other hand, the so-called "standard", $\mathrm{O}_{2}$-sensitive NiFe hydrogenase from Desulfovibrio fructosovorans (Hyn) can be made significantly resistant to $\mathrm{O}_{2}$ by replacing a conserved valine residue near the active site ${ }^{4}$ (figure 1 ) with a cystein. ${ }^{5}$ (Having any hydrophilic residue at that position in $D f$ Hyn enhances the rate of reactivation after oxidative inactivation ${ }^{6}$ and this position also determines the intramolecular diffusion rates. ${ }^{4}$ ) Escherichia coli expresses one hydrogenase from each group, Hyd-1 and Hyd-2, respectively. $1,7,8$

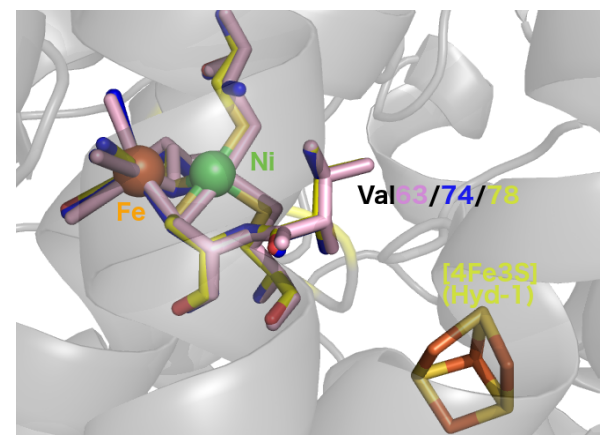

Figure 1. Overlay of the structures of the active site of E. coli Hyd$1 \mathrm{NiFe}$ hydrogenase (yellow), E. coli Hyd-2 (pink) and D. fructosovorans Hyn (blue), together with the conserved V74/V78 residue, and the proximal [4Fe3S] cluster of Hyd-1. pdb accession codes 3UQY, ${ }^{9}$ $6 \mathrm{EHQ}^{10}$ and $1 \mathrm{YQW} .{ }^{11}$

Lukey and coworkers have reported the production of recombinant Hyd-1 and Hyd-2 enzymes of E. coli, with the small subunit bearing a C-terminal $\mathrm{His}_{6}$-tag, from engineered oper- ons on the chromosome. ${ }^{7}$ On our side, we produced Hyd-1 (wild-type and V78C) and Hyd-2 enzymes from plasmids in the E. coli FTD147 (DE3) strain carrying chromosomal inframe deletions of the genes encoding the large subunits of hydrogenase- $1,-2$, and $-3 .{ }^{12-14}$ Recombinant Hyd-1 hydrogenases were produced as a dimeric and soluble form, consisting of the large (HyaB) and the small subunits (HyaA) only (figure $\mathrm{S} 1 \mathrm{~A})$. The C-terminal membrane-anchoring hydrophobic helix of HyaA was replaced with a Streptag II. Recombinant Hyd2 hydrogenase consists of $\mathrm{HybO}$ (the small subunit), whose C-terminal transmembrane domain was cleaved by a treatment with trypsin, and HybC (the large subunit) bearing a $\mathrm{N}$-terminal His ${ }_{6}$-tag (figure S1B). The enzymes Hyd1 and Hyd 2 characterized here appear to have greater and lower activity, respectively, that those prepared using the methods in 7. See in SI more information about the production and activity of these enzymes, and a comparison with previously published activity values.

We compared the properties of wild-type recombinant (WT) Hyd- 1 and the V78C variant using direct electrochemistry, 15,16 whereby the enzyme is adsorbed onto a rotating electrode and any change in current reports on a change in turnover frequency, resulting e.g. from exposure to inhibitors $\left(\mathrm{CO}\right.$ or $\left.\mathrm{O}_{2}\right)$ and/or redox-driven (in)activation.

Figure 2 compares the response of WT Hyd- 1 and V78C to transient exposures to $\mathrm{O}_{2}$. We produced "bursts" of $\mathrm{O}_{2}$ by injecting in the electrochemical cell small amounts of $\mathrm{O}_{2-}$ saturated solution while simultaneously flushing the solution with $\mathrm{H}_{2}$. In both cases the inhibition is reversed by removing $\mathrm{O}_{2}$ : the enzymes reactivate after exposure to $\mathrm{O}_{2}$, even under the very oxidizing conditions used here to prevent the direct reduction of $\mathrm{O}_{2}$ on the electrode $(+140 \mathrm{mV})$. All things being equal, the V78C variant is less inhibited than the WT enzyme.

We determined the rate constants of inactivation $\left(k_{\mathrm{i}}^{\mathrm{O}_{2}}\right)$ and reactivation $\left(k_{\mathrm{a}}^{\mathrm{O}_{2}}\right)$ in this experiment by fitting ${ }^{18}$ a model ${ }^{4}$ which assumes that the $\mathrm{O}_{2}$-adduct can also irreversibly inactivate (with 1 st-order rate constant $k_{3}$ ):

$$
\text { active } \stackrel{\frac{k_{\mathrm{i}}^{\mathrm{O}_{2}} \times\left[\mathrm{O}_{2}\right]}{\rightleftharpoons}}{k_{\mathrm{a}}} \text { adduct } \stackrel{k_{3}}{\longrightarrow} \text { dead end }
$$

The rate constants in Table 1 show that V78C inactivates about 5-times more slowly than the WT; the mutation has a smaller effect on the reactivation rate. Whereas the inactivation of the WT enzyme is fully reversible $\left(k_{3}=0\right)$, we found that the V78C data are best described using a small value of $k_{3} \approx 0.001 \mathrm{~s}^{-1}$.

To determine whether the V78C-induced decrease in the rate of reaction with $\mathrm{O}_{2}$ is due to the mutation hindering the diffusion along the gas channel, we compared the rates of inhibition of the enzymes by $\mathrm{CO}$, which reports on the rate of intramolecular diffusion. ${ }^{4,16,19}$ Figure 3 shows the response of 
Table 1. Kinetic properties of NiFe hydrogenases

\begin{tabular}{|c|c|c|c|c|c|c|c|c|}
\hline enzyme & $\begin{array}{l}k_{\mathrm{i}}^{\mathrm{O}_{2}} \\
\left(\mathrm{mM}^{-1} \mathrm{~s}^{-1}\right)\end{array}$ & $\begin{array}{l}k_{\mathrm{a}}^{\mathrm{O}_{2}} \\
\left(\mathrm{~s}^{-1}\right) \text { at } 140 \mathrm{mV}\end{array}$ & $\begin{array}{l}k_{\text {in }}^{\text {app,CO }} \\
\left(\mathrm{mM}^{-1} \mathrm{~s}^{-1}\right)\end{array}$ & $\begin{array}{l}k_{\text {in }}^{\mathrm{CO}} \\
\left(\mathrm{mM}^{-1} \mathrm{~s}^{-1}\right)\end{array}$ & $\begin{array}{l}k_{\text {out }}^{\mathrm{CO}} \\
\left(\mathrm{s}^{-1}\right)\end{array}$ & $\begin{array}{l}K_{I}^{C O} \\
(\mu \mathrm{M})\end{array}$ & $\begin{array}{l}K_{m} \\
\left(\operatorname{mbar} \mathrm{H}_{2}\right)^{i}\end{array}$ & refs \\
\hline$\overline{E c ~ H y d-1 ~ W T}$ & $20 \pm 3^{a}$ & $0.16 \pm 0.02^{a}$ & $1.5 \pm 0.7^{e}$ & $376 \pm 176^{e}$ & $0.9 \pm 0.2^{e}$ & $2.4^{e}$ & $4 \pm 2^{e}$ & this work \\
\hline Ec Hyd-1 V78C & $4 \pm 1^{a}$ & $0.24 \pm 0.09^{a}$ & $1.5 \pm 0.6^{e}$ & $16 \pm 6^{e}$ & $0.6 \pm 0.2^{e}$ & $38^{e}$ & $100 \pm 7^{e}$ & this work \\
\hline Ec Hyd-2 WT & $5 \pm 1^{a}$ & $0.002 \pm 0.001^{a}$ & $>20^{e}$ & $>1000^{e}$ & $>2^{e}$ & $0.9^{e}$ & $19 \pm 6^{e}$ & this work \\
\hline Df Hyn WT & $30^{b}$ & $\mathrm{n} / \mathrm{a}$ & & $63000^{e}, 2000^{f}$ & $500^{e}, 2^{f}$ & $0.65^{e}$ & $10 \pm 5^{h}$ & $4,5,19,20$ \\
\hline Df Hyn V74C & $10^{c}$ & $0.001^{c}$ & & $120 \pm 50^{g}$ & $1.5 \pm 0.5^{g}$ & & $610 \pm 320^{h}$ & 5,6 \\
\hline$A a \mathrm{WT}$ & $2.5^{d}$ & $0.004^{d}$ & $\mathrm{n} / \mathrm{a}$ & $\mathrm{n} / \mathrm{a}$ & $\mathrm{n} / \mathrm{a}$ & $\mathrm{n} / \mathrm{a}$ & $\mathrm{n} / \mathrm{d}$ & 21 \\
\hline
\end{tabular}

Experimental conditions: ${ }^{a} 40^{\circ} \mathrm{C}, \mathrm{pH} 6,+140 \mathrm{mV} ;{ }^{b} 40^{\circ} \mathrm{C}, \mathrm{pH} 7,+200 \mathrm{mV}$, no significant differences were found between $\mathrm{pH} 7$ and 6 or between $+200 \mathrm{mV}$ and $+140 \mathrm{mV} ;{ }^{20}{ }^{c} 40^{\circ} \mathrm{C}, \mathrm{pH} 5.5,+140 \mathrm{mV} ;{ }^{d} 40^{\circ} \mathrm{C}, \mathrm{pH} 7,+140 \mathrm{mV} ;{ }^{e} 40^{\circ} \mathrm{C}, \mathrm{pH} 6,-60 \mathrm{mV} ;{ }^{\circ} 9^{\circ} \mathrm{C}, \mathrm{pH} 7,-160 \mathrm{mV}$; $89^{\circ} \mathrm{C}, \mathrm{pH} 5.5,-160 \mathrm{mV} ;{ }^{h} \mathrm{pH} 7,-160 \mathrm{mV}$, no significant effect of varying the temperature was detected. ${ }^{i} 1 \mathrm{mbar}$ of $\mathrm{H}_{2}$ is equivalent to $0.8 \mu \mathrm{M}$ of dissolved $\mathrm{H}_{2} \cdot{ }^{22}$

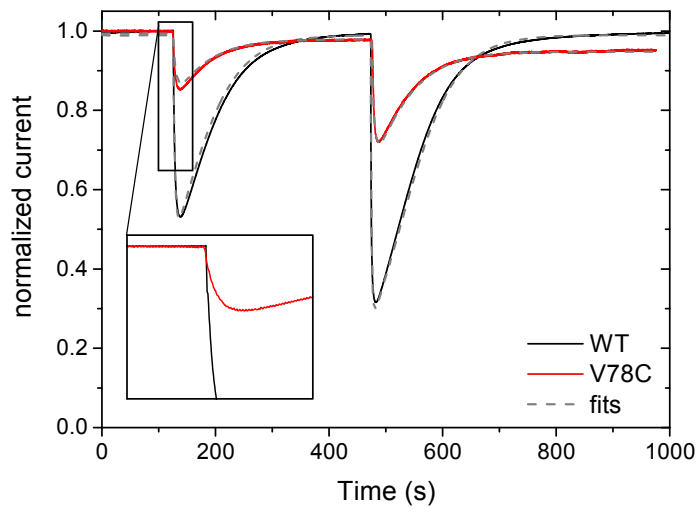

Figure 2. Aerobic inhibition of Hyd-1 WT (black) and V78C (red) $E_{C}$ Hyd-1. The current was divided by the baseline to remove the effect of film loss and anaerobic inactivation. ${ }^{17}$ The grey dashed line is the best fit of the model in eq. $1 .^{4}\left[\mathrm{O}_{2}\right]=8$ and $20 \mu \mathrm{M}$ injected at 125 and $475 \mathrm{~s}$ respectively, $E=+140 \mathrm{mV}$ vs SHE, $\omega=3000 \mathrm{rpm}$, 1 bar $\mathrm{H}_{2}, 40^{\circ} \mathrm{C}, \mathrm{pH} 6$.

the two enzymes to a transient exposure to $\mathrm{CO}$. We measured the rates of $\mathrm{CO}$ binding $\left(k_{\text {in }}^{\text {app, } \mathrm{CO}}\right)$ and release $\left(k_{\text {out }}^{\mathrm{CO}}\right)$ listed Table 1 by fitting the following model

$$
\text { active } \frac{k_{\text {in }}^{\text {app, } \mathrm{CO}} \times[\mathrm{CO}]}{k_{\text {out }}^{\mathrm{CO}}} \text { inactive }
$$

Since $\mathrm{CO}$ competes with $\mathrm{H}_{2}, 4,20$ the apparent rate of $\mathrm{CO}$ binding $k_{\text {in }}^{\text {app,CO }}$ is lower than the rate of binding in the absence of $\mathrm{H}_{2}$ by a factor $\left(1+\left[\mathrm{H}_{2}\right] / K_{m}\right)$. We measured the Michaelis constants $\left(K_{m}\right)$ by examining how the steady-state $\mathrm{H}_{2}$-oxidation current depends on $\mathrm{H}_{2}$ concentration: the results in figure 4 show that the mutation greatly increases $K_{m}$. We confirmed the low value of $K_{m}$ for Hyd-1 WT by running experiments such as those described in ref. 4 , where the current is measured as a function of time while the $\mathrm{H}_{2}$ concentration is decreasing (see SI figure S2). The V78C mutation increases the value of $K_{m}$ 25-fold (Table 1). ${ }^{23}$

We used the measured values of $K_{m}$ to correct the apparent rates of $\mathrm{CO}$ inhibition and obtain the true values of $k_{\text {in }}^{\mathrm{CO}} .4,20$ The results in table 1 show that the rate of $\mathrm{CO}$ binding for the V78C variant is one order of magnitude slower than for the WT, which would have escaped detection if we had not measured the $K_{m}$ values.

The effect of the mutation on the kinetics of reversible oxida-

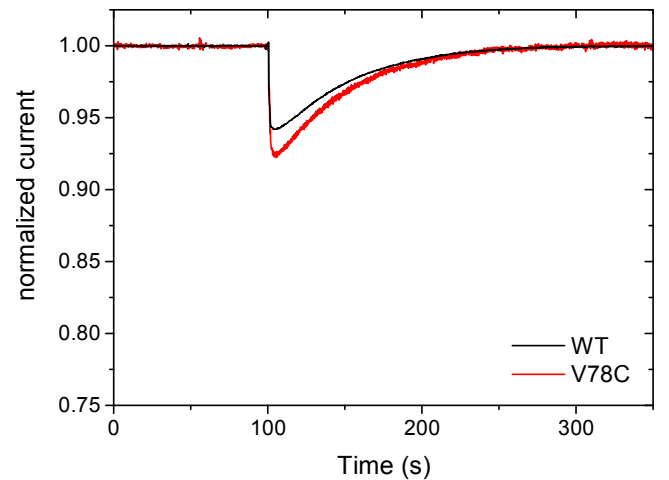

Figure 3. Effect of transient exposure to $\mathrm{CO}$ on the catalytic current of Hyd-1 WT (black) and V78C (red). [CO] $=38 \mu \mathrm{M}, E=-60 \mathrm{mV}$ vs SHE, $\omega=3000 \mathrm{rpm}, 1$ bar $\mathrm{H}_{2}, 40^{\circ} \mathrm{C}$, $\mathrm{pH} 6$.

tive inactivation can be assessed under anaerobic conditions in voltammetric experiments, where the electrode potential is swept and the slow, redox-driven conversion between active and inactive states produces a hysteresis. ${ }^{24}$ Reactivation occurs on the sweep to low potential because the rate of reactivation increases as the electrode potential decreases. The "switch potential" $E_{\mathrm{SW}}$ where the activity returns on the downward trace, is the potential below which the reactivation becomes faster than the voltammetric time scale ( $F v / R T$, where $v$ is the scan rate): the faster the reactivation or the slower the scan rate, the greater $E_{\mathrm{sw}} \cdot{ }^{6,25}$ The V78C mutation shifts $E_{\mathrm{sw}}$ up by about $25 \mathrm{mV}$, and thus increases the rate of reactivation after anaerobic oxidative inactivation by a factor of about 2 . We calculate from figure 5 the rates of reactivation at $E_{\mathrm{sw}}=140 \mathrm{mV}$ after anaerobic inactivation to be $F v / R T=0.10 \mathrm{~s}^{-1}$ for WT Hyd-1, hence $0.19 \mathrm{~s}^{-1}$ for V78C. These rates are similar to those measured for the reactivation after aerobic inactivation ( 0.16 and $0.24 \mathrm{~s}^{-1}$ in Table 1$)$ : in both forms of the enzyme, the species formed under oxidative aerobic and anaerobic conditions reactivate at the same rate, and thus are likely to be the same.

Table 1 also shows kinetic parameters measured with Hyd2 (SI figures S3-S5). Its inhibition by $\mathrm{CO}$ is fast at $40^{\circ} \mathrm{C}$ and only lower values of the binding and release rates could be estimated, but their ratio $K_{I}^{\mathrm{CO}}$ is easily measured and well defined.

Overall, the above data provide a fresh perspective on the reactivity of $\mathrm{NiFe}$ hydrogenases with inhibitors, and new evidence that it is strongly affected by the protein matrix. 


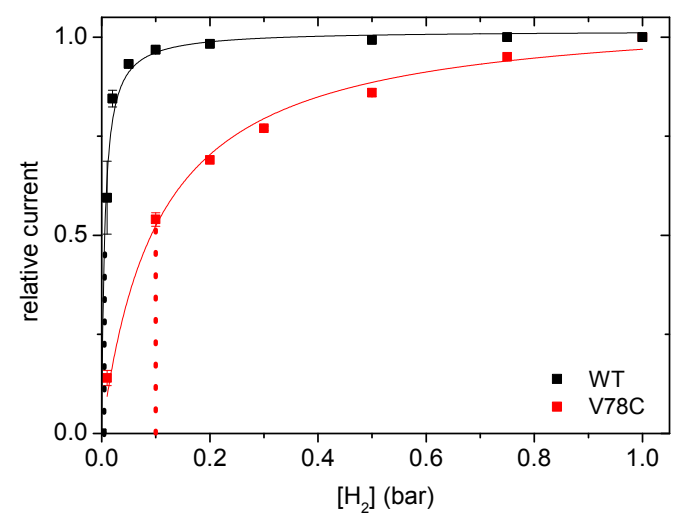

Figure 4. Steady-state current against $\left[\mathrm{H}_{2}\right]$ from chronoamperometry experiments with Hyd-1 WT (black) and V78C (red). The dotted lines mark the Michaelis constants. $E=-60 \mathrm{mV}$ vs SHE, $\omega=3000$ rpm, $T=40^{\circ} \mathrm{C}, \mathrm{pH} 6$.
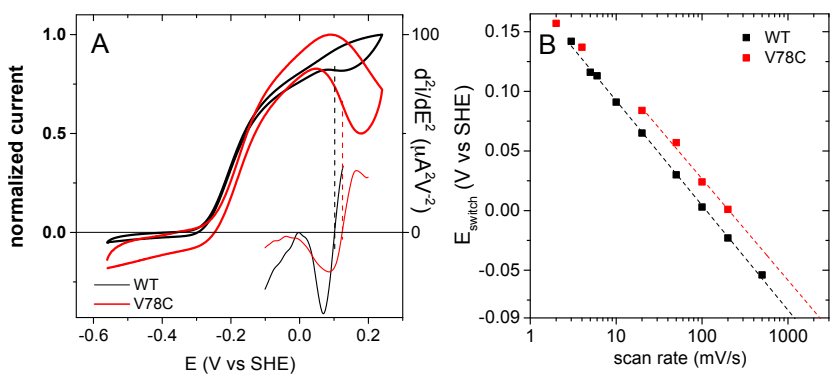

Figure 5. Effect of the V78C mutation on the anaerobic inactivation and reactivation of Hyd-1. Panel A: Cyclic voltammograms (thick lines, left axis) at $5 \mathrm{mV} / \mathrm{s}$ of Hyd-1 WT (black) and V78C (red) adsorbed at a rotating disk electrode and their second derivative (thin lines, right axis). The $E_{\mathrm{sw}}$ values are indicated by dashed lines. Panel B: Influence of scan rate on $E_{\mathrm{sw}}$ for Hyd-1 WT (black) and V78C (red). The slopes of the dashed lines are 85 and $89 \mathrm{mV} /$ decade (V78C and WT, respectively). ${ }^{26} 1$ bar $\mathrm{H}_{2}, \mathrm{~T}=40^{\circ} \mathrm{C}$, mixed buffer $\mathrm{pH} 6$.

Escherichia coli Hyd-1 is much less inhibited by $\mathrm{CO}$ than Hyd-2. ${ }^{7}$ This may be a general property of $\mathrm{O}_{2}$-resistant $\mathrm{NiFe}$ hydrogenases: the enzyme from Aquifex aeolicus is apparently not inhibited by $\mathrm{CO}$ (unpublished results of ours) and according to a FTIR investigation, interacts weakly with $\mathrm{CO} .{ }^{27}$ Here we reported inhibition constants $\left(K_{I}^{\prime}\right.$ 's), but also, and for the first time, the rates of $\mathrm{CO}$ binding and release for an $\mathrm{O}_{2}$-resistant $\mathrm{NiFe}$ hydrogenase (Table 1). The most significant difference between Hyd-1 and Hyd-2 is actually the kinetics of inhibition, which is much slower for the $\mathrm{O}_{2}$-resistant $E c$ Hyd-1 than for standard hydrogenases ( $E c$ Hyd-2 or $D f \mathrm{Hyn}$ ).

Previously, based on the characterization of a large series of site-directed variants of $D f \mathrm{Hyn}$, we have shown that the rate of inhibition by $\mathrm{CO}$ is a proxy of the rate of intramolecular diffusion (in this enzyme, CO-binding at the active site is very fast and does not limit the rate of inhibition). To support the hypothesis that this is also true for $E c$ Hyd-1, we note that the effect of the V-to-C mutation is about the same in $D f \mathrm{Hyn}$ and $E_{c}$ Hyd-1: a 15 to 25-fold decrease in $k_{\text {in }}^{\mathrm{CO}}$, a 25 to 60-fold increase in $K_{m}$, suggesting that the V-to-C mutations slow the rates of intramolecular diffusion of $\mathrm{CO}, \mathrm{H}_{2}$ (and probably also $\mathrm{O}_{2}$ ) in both enzymes. If so, the data in Table 1 show that something specific about the structure of $\mathrm{O}_{2}$ resistant NiFe hydrogenases significantly slows the diffusion of small ligands.
Simulations have been performed to probe this process in both standard ${ }^{28,29}$ and $\mathrm{O}_{2}$-resistant ${ }^{30-32} \mathrm{NiFe}$ hydrogenases; it has been proposed that the latter have narrower tunnels with fewer openings, which may indeed contribute to slowing down the intramolecular diffusion of small molecules.

Table 1 shows that the rates of binding and release of $\mathrm{CO}$ are much more variable than the rates of $\mathrm{O}_{2}$-binding, which differ less than ten-fold. Hyd-1 reacts with $\mathrm{O}_{2}$ much more slowly than with $\mathrm{CO}$, and since there is no reason to assume that these two ligands diffuse in the enzyme at different rates, the difference clearly indicates that intramolecular diffusion is not the rate limiting step of inhibition by $\mathrm{O}_{2}$. Therefore, the decrease in the rate of reaction with $\mathrm{O}_{2}$ that results from the V74C in Df Hyn or the V78C mutation in Ec Hyd-1 does not result from the channel being obstructed and the diffusion hindered, but rather from a change in the reactivity of the active site.

We have observed before that replacing V74 in $D f$ Hyn changes the rate of reactivation after oxidative inactivation by orders of magnitude, ${ }^{6}$ the reactivation is particularly fast in the V74C variant. ${ }^{5}$ A surprise in our study of $E c$ V78C Hyd-1 is that the effect is qualitatively the same as, but quantitatively much smaller than in $D f \mathrm{Hyn}$. The data in figure 5 show that the reactivation rate increases only two-fold in Ec V78C Hyd-1, compared to 25-fold in $D f$ V74C Hyn (data at $E=-90 \mathrm{mV}$ from ref. 5). But similar to our previous conclusion with $D f$ Hyn, we see that in the WT just like in the V78C mutant, the rates of reactivation after aerobic and anaerobic inactivation are the same, suggesting that the species formed under aerobic and anaerobic conditions are the same. ${ }^{33}$

Among NiFe hydrogenases for which electrochemical data are available, the V78C Hyd-1 mutant appears to be the most tolerant towards $\mathrm{CO}$ and $\mathrm{O}_{2}$. The $k_{\text {in }}^{\mathrm{CO}}$ values of Hyd-1 WT and $\mathrm{V} 78 \mathrm{C}$ are, respectively, two and three orders of magnitude smaller than that of $D f$ WT $\left(63000 \mathrm{mM}^{-1} \mathrm{~s}^{-1}\right.$, extrapolated to $\left.40^{\circ} \mathrm{C}\right)$. The rate of reaction with $\mathrm{O}_{2}\left(4 \mathrm{~s}^{-1} \mathrm{mM}^{-1}\right)$ is in the lower range of the values obtained with $\mathrm{NiFe}$ hydrogenases (from 2 to $30 \mathrm{~s}^{-1} \mathrm{mM}^{-1}$ ) and the reactivation at $140 \mathrm{mV}$ after exposure to $\mathrm{O}_{2}$ is about two orders of magnitude faster than the rates found for $D f \mathrm{~V} 74 \mathrm{C}$, Hyd-2 or the $\mathrm{O}_{2}$-resistant hydrogenase from $A a$ (see table 1). The reactivation rate constants extrapolated to $E=-90 \mathrm{mV}$ from the data in figure 5 are 50 and $90 \mathrm{~s}^{-1}$ for Hyd-1 WT and V78C, respectively, which is 3 orders of magnitude faster than $D f \mathrm{WT}\left(0.02 \mathrm{~s}^{-1}\right.$ in ref. 5) and also faster than $D f \operatorname{V} 74 \mathrm{C}\left(0.5 \mathrm{~s}^{-1}\right)^{5}$ and Aa WT $\left.\left(5 \mathrm{~s}^{-1}\right)^{25}\right)$.

Our results show that a mutation that makes standard NiFe hydrogenase resist $\mathrm{O}_{2}$ can be transposed into an enzyme that is already resistant. The effects of the mutation on $k_{\text {in }}^{\mathrm{O}_{2}}, k_{\text {in }}^{\mathrm{CO}}$, and $K_{m}$ are qualitatively the same in Df Hyn and Ec Hyd-1, so that the beneficial effect of the mutation improves further the properties of the naturally resistant enzyme. One problem though is the $\sim 20$ fold lower activity of the V78C mutant compared to Hyd-1 WT. In Df Hyn V74C, the residue C74 binds the $\mathrm{Ni}$ in the as-prepared enzyme, ${ }^{34}$ but a normal coordination can be restored upon reduction. ${ }^{5}$ It may be that this perturbed structure is also present in $E c$ Hyd-1 V78C, but too stable to be transformed back to the normal state; indeed, we could not observe with the V78C Ec hyd1 variant the reductive activation observed with V74C Df $\mathrm{Hyn}^{5}$.

\section{Associated content}

Authors information

Corresponding authors: $\star$ mbrugna@imm.cnrs.fr,

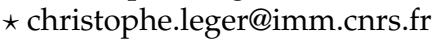

Authors contributions 
The manuscript was written through contributions of all authors.

Supporting Information Available: A SI file is available free of charge: materials and methods (section S1), SDS-PAGE of purified Hyd-1 and Hyd-2 enzymes (Figure S1), measurement of $K_{m}$ for Hyd-1 WT (Figure S2), measurement of $K_{m}$ for Hyd-2 (Figure S3), effect of $\mathrm{O}_{2}$ on Hyd-2 (Figure S4), effect of $\mathrm{CO}$ on Hyd-2 (Figure S5). This material is available free of charge via the Internet at http://pubs . acs . org/.

Acknowledgement The authors thank F. Sargent (University of Dundee, UK) and S.R. Kushner (University of Georgia, USA) for kindly providing the E. coli FTD147 strain and the plasmid pMAK705, respectively. Our work is supported by CNRS, Aix Marseille Université, Agence Nationale de la Recherche (ANR-14-CE05-0010), and the Excellence Initiative of Aix-Marseille University - A*MIDEX, a French "Investissements d'Avenir" programme (ANR-11-IDEX-0001-02). The authors are part of the French bioinorganic chemistry network (www.frenchbic.cnrs.fr)

\section{Notes and References}

(1) Lukey, M. J.; Roessler, M. M.; Parkin, A.; Evans, R. M.; Davies, R. A.; Lenz, O.; Friedrich, B.; Sargent, F.; Armstrong, F. A. Oxygen-Tolerant [NiFe]-Hydrogenases: The Individual and Collective Importance of Supernumerary Cysteines at the Proximal Fe-S Cluster. J. Am. Chem. Soc. 2011, 133, 16881-16892.

(2) Goris, T.; Wait, A. F.; Saggu, M.; Fritsch, J.; Heidary, N.; Stein, M. Zebger, I.; Lendzian, F.; Armstrong, F. A.; Friedrich, B.; Lenz, O. A Unique Iron-Sulfur Cluster is Crucial for Oxygen Tolerance of a [NiFe]-Hydrogenase. Nat. Chem. Biol. 2011, 7, 310-318.

(3) Hartmann, S.; Frielingsdorf, S.; Ciaccafava, A.; Lorent, C.; Fritsch, J.; Siebert, E.; Priebe, J.; Haumann, M.; Zebger, I.; Lenz, O. Activation by an Isolated Large Subunit of a [NiFe] Hydrogenase. Biochemistry 2018, 57, 5339-5349.

(4) Liebgott, P.-P.; Leroux, F.; Burlat, B.; Dementin, S.; Baffert, C.; Lautier, T.; Fourmond, V.; Ceccaldi, P.; Cavazza, C.; Meynial-Salles, I. Soucaille, P.; Fontecilla-Camps, J. C.; Guigliarelli, B.; Bertrand, P. Rousset, M.; Léger, C. Relating Diffusion along the Substrate Tunnel and Oxygen Sensitivity in Hydrogenase. Nat. Chem. Biol. 2009, 6, 63-70

(5) Liebgott, P.-P.; de Lacey, A. L.; Burlat, B.; Cournac, L.; Richaud, P.; Brugna, M.; Fernandez, V. M.; Guigliarelli, B.; Rousset, M.; Léger, C.; Dementin, S. Original Design of an Oxygen-Tolerant [NiFe] Hydrogenase: Major Effect of a Valine-to-Cysteine Mutation near the Active Site. J. Am. Chem. Soc. 2011, 133, 986-997.

(6) Hamdan, A. A.; Liebgott, P.-P.; Fourmond, V.; Gutiérrez-Sanz, O.; De Lacey, A. L.; Infossi, P.; Rousset, M.; Dementin, S.; Léger, C. Relation Between Anaerobic Inactivation and Oxygen Tolerance in a Large Series of NiFe Hydrogenase Mutants. Proc. Natl. Acad. Sc. USA 2012, 109, 19916-19921.

(7) Lukey, M. J.; Parkin, A.; Roessler, M. M.; Murphy, B. J.; Harmer, J.; Palmer, T.; Sargent, F.; Armstrong, F. A. How Escherichia coli Is Equipped to Oxidize Hydrogen under Different Redox Conditions. J. Biol. Chem. 2010, 285, 3928-3938.

(8) Sargent, F. The Model [NiFe]-Hydrogenases of Escherichia coli. Advances in microbial physiology 2016, 68, 433-507.

(9) Volbeda, A.; Amara, P.; Darnault, C.; Mouesca, J.-M.; Parkin, A.; Roessler, M. M.; Armstrong, F. A.; Fontecilla-Camps, J. C. X-ray Crystallographic and Computational Studies of the $\mathrm{O}_{2}$-Tolerant [NiFe]Hydrogenase 1 from Escherichia coli. Proc. Natl. Acad. Sc. USA 2012, 109, 5305-5310.

(10) Beaton, S. E.; Evans, R. M.; Finney, A. J.; Lamont, C. M.; Armstrong, F. A.; Sargent, F.; Carr, S. B. The Structure of Hydrogenase-2 from Escherichia coli: Implications for $\mathrm{H}_{2}$-Driven Proton Pumping Biochem. J. 2018, 475, 1353-1370.

(11) Volbeda, A.; Martin, L. Cavazza, C.; Matho, M. Faber, B. W. Roseboom, W.; Albracht, S. P.; Garcin, E.; Rousset, M.; FontecillaCamps, J. C. Structural Differences between the Ready and Unready Oxidized States of [NiFe] Hydrogenases. J. Biol. Inorg. Chem. 2005, 10, 239-249.

(12) Redwood, M. D.; Mikheenko, I. P.; Sargent, F.; Macaskie, L. E. Dissecting the Roles of Escherichia coli Hydrogenases in Biohydrogen Production. FEMS Microbiology Letters 2008, 278, 48-55.

(13) Skibinski, D. A. G.; Golby, P.; Chang, Y.-S.; Sargent, F.; Hoffman, R Harper, R.; Guest, J. R.; Attwood, M. M.; Berks, B. C.; Andrews, S. C. Regulation of the Hydrogenase-4 Operon of Escherichia coli by the Sigma(54)-Dependent Transcriptional Activators FhlA and HyfR. J
Bacteriol 2002, 184, 6642-6653.

(14) Weyman, P. D.; Vargas, W. A.; Tong, Y.; Yu, J.; Maness, P.-C. Smith, H. O.; Xu, Q. Heterologous Expression of Alteromonas macleodii and Thiocapsa roseopersicina [NiFe] Hydrogenases in Synechococcus elongatus. PLOS ONE 2011, 6, 1-8

(15) Sensi, M.; del Barrio, M.; Baffert, C.; Fourmond, V.; Léger, C. New Perspectives in Hydrogenase Direct Electrochemistry. Curr. Op. Electrochem. 2017, 5, 135-145.

(16) del Barrio, M.; Sensi, M.; Orain, C.; Baffert, C.; Dementin, S.; Fourmond, V.; Léger, C. Electrochemical Investigations of Hydrogenases and Other Enzymes That Produce and Use Solar Fuels. Acc. Chem. Res. 2018, 51, 769-777.

(17) Fourmond, V.; Lautier, T.; Baffert, C.; Leroux, F.; Liebgott, P.-P.; Dementin, S.; Rousset, M.; Arnoux, P.; Pignol, D.; Meynial-Salles, I.; Soucaille, P.; Bertrand, P.; Léger, C. Correcting for Electrocatalyst Desorption and Inactivation in Chronoamperometry Experiments. Anal. Chem. 2009, 81, 2962-2968.

(18) Fourmond, V. QSoas: A Versatile Software for Data Analysis. Anal. Chem. 2016, 88, 5050-5052.

(19) Leroux, F.; Dementin, S.; Burlat, B.; Cournac, L.; Volbeda, A.; Champ, S.; Martin, L.; Guigliarelli, B.; Bertrand, P.; FontecillaCamps, J.; Rousset, M.; Léger, C. Experimental Approaches to Kinetics of Gas Diffusion in Hydrogenase. Proc. Natl. Acad. Sc. USA 2008, 105, 11188-11193.

(20) Léger, C.; Dementin, S.; Bertrand, P.; Rousset, M.; Guigliarelli, B. Inhibition and Aerobic Inactivation Kinetics of Desulfovibrio fructosovorans NiFe Hydrogenase Studied by Protein Film Voltammetry. J. Am. Chem. Soc. 2004, 126, 12162-12172.

(21) Pandelia, M.-E.; Fourmond, V.; Tron-Infossi, P.; Lojou, E.; Bertrand, P.; Léger, C.; Giudici-Orticoni, M.-T.; Lubitz, W. Membrane-Bound Hydrogenase I from the Hyperthermophilic Bacterium Aquifex aeolicus: Enzyme Activation, Redox Intermediates and Oxygen Tolerance. J. Am. Chem. Soc. 2010, 132, 6991-7004.

(22) Crozier, T. E.; Yamamoto, S. Solubility of Hydrogen in Water, Sea Water, and Sodium Chloride Solutions. Journal of Chemical \& Engineering Data 1974, 19, 242-244.

(23) The $K_{m}$ values reported here for the Hyd-1 and Hyd-2 hydrogenases are similar to those obtained previously. 7,10

(24) Jones, A. K.; Lamle, S. E.; Pershad, H. R.; Vincent, K. A.; Albracht, S. P. J.; Armstrong, F. A. Enzyme Electrokinetics: Electrochemical Studies of the Anaerobic Interconversions between Active and Inactive States of Allochromatium vinosum [NiFe]-hydrogenase. J. Am. Chem. Soc. 2003, 125, 8505-8514.

(25) Fourmond, V.; Infossi, P.; Giudici-Orticoni, M.-T.; Bertrand, P.; Léger, C. "Two-Step" Chronoamperometric Method for Studying the Anaerobic Inactivation of an Oxygen Tolerant NiFe Hydrogenase. J. Am. Chem. Soc. 2010, 132, 4848-4857.

(26) The slopes give $\alpha \approx 0.71$ in eq. 12 of ref. 25 , similar to the result obtained with Aquifex aeolicus NiFe hydrogenase.

(27) Pandelia, M.-E.; Infossi, P.; Giudici-Orticoni, M. T.; Lubitz, W. The Oxygen-Tolerant Hydrogenase I from Aquifex aeolicus Weakly Interacts with Carbon Monoxide: An Electrochemical and Time-Resolved FTIR Study. Biochemistry 2010, 49, 8873-8881.

(28) Wang, P.-H. H.; Best, R. B.; Blumberger, J. Multiscale Simulation Reveals Multiple Pathways for $\mathrm{H}_{2}$ and $\mathrm{O}_{2}$ Transport in a [NiFe]Hydrogenase. J. Am. Chem. Soc. 2011, 133, 3548-3556.

(29) Wang, P.-H. H.; Blumberger, J. Mechanistic Insight into the Blocking of CO Diffusion in [NiFe]-Hydrogenase Mutants through Multiscale Simulation. PNAS 2012, 109, 6399-6404.

(30) Oteri, F.; Baaden, M.; Lojou, E.; Sacquin-Mora, S. Multiscale Simulations Give Insight into the Hydrogen in and out Pathways of [NiFe]-Hydrogenases from Aquifex aeolicus and Desulfovibrio fructosovorans. The journal of physical chemistry. B 2014, 118, 13800-13811.

(31) Kalms, J.; Schmidt, A.; Frielingsdorf, S.; van der Linden, P.; von Stetten, D.; Lenz, O.; Carpentier, P.; Scheerer, P. Krypton Derivatization of an $\mathrm{O}_{2}$-Tolerant Membrane-Bound [NiFe] Hydrogenase Reveals a Hydrophobic Tunnel Network for Gas Transport. Angew. Chem. Int. Ed. 2016, 55, 5586-5590

(32) Kalms, J.; Schmidt, A.; Frielingsdorf, S.; Utesch, T.; Gotthard, G.; von Stetten, D.; van der Linden, P.; Royant, A.; Mroginski, M. A. Carpentier, P.; Lenz, O.; Scheerer, P. Tracking the Route of Molecular Oxygen in $\mathrm{O}_{2}$-Tolerant Membrane-Bound [NiFe] Hydrogenase. Proc. Natl. Acad. Sc. USA 2018, 115, E2229-E2237.

(33) Abou Hamdan, A.; Burlat, B.; Gutiérrez-Sanz, O.; Liebgott, P.-P. Baffert, C.; De Lacey, A. L.; Rousset, M.; Guigliarelli, B.; Léger, C.; Dementin, S. $\mathrm{O}_{2}$-Independent Formation of the Inactive States of NiFe Hydrogenase. Nat. Chem. Biol. 2012, 9, 15-17.

(34) Volbeda, A.; Martin, L.; Liebgott, P.-P. P.; De Lacey, A. L.; FontecillaCamps, J. C. [NiFe]-Hydrogenases Revisited: Nickel-Carboxamido Bond Formation in a Variant with Accrued $\mathrm{O}_{2}$-Tolerance and a Tentative Re-interpretation of Ni-SI States. Metallomics 2015, 7, 710-718. 